\title{
The Impact of a Correctional-based Parenting Program in Strengthening Parenting Skills of Incarcerated Mothers
}

\author{
Victoria Perry, Cathrine Fowler, Kyleigh Heggie and Karen Barbara*
}

\begin{abstract}
Despite a relative paucity of information on the impact that incarceration of a parent has on a child, most literature agrees that the effects are real and profound. Corrective Services NSW (CSNSW) in conjunction with Tresillian Family Care Centres introduced a parenting program, Mothering at a Distance (MAAD), across correctional facilities for female prisoners in New South Wales (NSW), Australia. The central aim of the Program was to provide early parenting education and support intervention to mothers in custody, with the aim of guarding against the intergenerational cycle of crime. The Program intended to enhance a prisoner's ability to provide appropriate and sensitive parenting and reduce the emotional and social impact of separation on their children. An evaluation of the Program's development, implementation, effectiveness, and sustainability was conducted on all groups run between October 2006 and December 2008. This article provides a summary of the evaluation findings.
\end{abstract}

\section{Introduction}

The Mothering at a Distance (MAAD) Program was developed in response to an identified need for the provision of parenting programs for incarcerated mothers, and focused on enhancing the relationship between the mother and young child, rather than on the mechanics of parenting. The Program was a collaborative project of Corrective Services NSW (CSNSW) and Tresillian Family Care Centres (an early parenting support service). It was funded by the Australian Government.

It is generally accepted that the relationship between a young child and their main caregiver is critical in influencing the child's social, emotional and physical development

* Victoria Perry is the Research and Information Manager with Corporate Research, Evaluation and Statistics (CRES), Corrective Services NSW (CSNSW) and has a research background in child and family psychology, family conflict and child abduction. Cathrine Fowler is a child and family health nurse and is the Professor for the Tresillian Chair in Child and Family Health Nursing. She has extensive experience working with parents and their young children. Kyleigh Heggie is the Assistant Director (CRES), CSNSW and has an extensive research background in criminological and penological research. Karen Barbara is a Research Officer (CRES), in CSNSW and has a background in information and communication. 
(National Scientific Council on the Developing Child 2004a; 2004b). Many women in custody have reported experiencing family and other violence, as well as substance abuse, as children (see Anti-Discrimination Commission Queensland 2006; Butler and Milner 2003; WA Department of Corrective Services 2009; Victorian Health Promotion Foundation 2004). In many instances, the cycle of intergenerational violence and substance abuse perpetuates due to the lack of positive parenting models (Dawe et al. 2007).

The MAAD Program aimed to assist mothers in custody to gain skills to enhance their ability to parent in a sound and appropriate manner. The Program focuses on 'strengths' and 'relationship' based approaches. The program outcomes are of crucial importance due to the paucity of research evidence for the effectiveness of parenting programs within Australian correctional systems.

\section{The Effects of Parental Incarceration on a Child}

Between 1998 and 2008, Australia experienced a 39 per cent increase in the prison population, with the 2008 Australian prison census counting 27,615 people in custody (Australian Bureau of Statistics 2008). Women are a minority group within the prison system, accounting for a total of 7.4 per cent of the NSW full-time prison population in 2006/07. However, their rate of imprisonment is steadily increasing, and at a greater rate than that of their male counterparts. The NSW female prison population increased by 99 per cent between 1997 and 2007, in comparison to a 46 per cent increase in the male prison population (calculated from the NSW Inmate Census 2007: Corben 2008).

Incarceration does not just adversely affect those residing within the prison walls; it also affects children who may be dependent on those in custody. Children of prisoners are at increased risk of experiencing mental, emotional, physical and financial hardships as a result of the incarceration of a parent. With the rates of imprisonment increasing, particularly for women who are often the primary caregivers of children, there can be no doubt that the lives of an increasing number of children are being dramatically affected by the incarceration of one, or both, parents.

In 2004, it was estimated that approximately 60,122 children in NSW under the age of 16 years had experienced parental incarceration at some point in their lives, representing 4.3 per cent of all children and 20.1 per cent of all Indigenous children (Quilty et al. 2004). A 1999 study conducted in NSW estimated that on any given day there were in excess of 11,000 children in NSW with a parent who is imprisoned (cited in Loy 2000). It is likely that this estimated figure has increased due to the rise in the overall prison population in the past 10 years.

Despite a relative dearth of research investigating the impact of parental incarceration on a child, most literature suggests that the children of incarcerated parents will experience a wide range of adverse emotional and financial effects. These effects can include social stigmatisation and isolation, financial strain, relocation (possibly foster care), disrupted education, and a decreased feeling of safety and security (Tudball 2000; Cunningham 2001; Miller 2006).

The effects of parental incarceration can also be psychological and may include experiences of anxiety, depression, shame and guilt, particularly if a child witnessed their parent's arrest (Tudball 2000; Cunningham 2001; Miller 2006). If relocation occurs, 
children may experience further strain through the loss of support networks, and separation from siblings if they cannot continue to be housed together (Travis 2005).

Additional trauma may be experienced by a child if separated from the primary caregiver (Travis 2005; Woodward 2003). As women are more commonly the primary caregiver and, in the majority of cases the sole parent before imprisonment, it has been argued that the 'children of female prisoners may experience greater disruption as a result of incarceration than those of male inmates' (Woodward 2003: viii). In support of this argument, Healy, Foley and Walsh (2000) found that the gender of the incarcerated parent was a significant factor in the stability of care arrangements for the children of prisoners. They found that children of male prisoners were more likely to be cared for by the non-incarcerated parent, than children of female prisoners, who are more likely to be cared for by grandparents, aunts and uncles or a foster carer.

Arguably, the most detrimental effect of parental incarceration is the risk it poses to the child-parent attachment, especially if the relationship was close before incarceration. In particular, early maternal separation and interruptions to the attachment-bonding process have been identified as causing serious long-term emotional difficulties (Woodward 2003). The impact of a break in parent-child attachment can lead to maladaptive coping mechanisms by the child, including truancy at school. This may, in turn, lead to a decrease in school attainment or cognitive development, drug and alcohol use, and other disruptive or antisocial behaviours. Not only will this behaviour pattern be difficult for the carer to manage, but it may also have long-term consequences for the child, particularly if no intervention occurs (Travis 2005).

It is often very difficult to maintain the parent-child bond when a parent is incarcerated. Parents may be housed in prisons far away from the family home, making it difficult to visit. In addition, carers may delay or decline the child's visit, believing it to be too distressing for the child to visit their parent in prison (Miller 2006). Although written contact is encouraged, some parents may be illiterate or children too young to benefit from this type of communication. Telephone access can be expensive, and calls may not be allowed until night time, when children may already be asleep and unable to talk (Bushfield 2004).

Maintaining a parenting role is often difficult for prisoners. Studies conducted by the Victorian Association for the Care and Resettlement of Offenders (VACRO) (Tudball 2000) and Healy, Foley and Walsh (2001) found that a variety of parenting issues were of concern for prisoners. The range of parental concerns most commonly identified by prisoners included:

- loss of parental authority over their children

- inability to protect their children

- physical separation from their children

- emotional distancing in their parent-child relationships

- decreased capacity to participate in decision-making regarding their children

- loss of day-to-day contact with their children

- feeling out-of-touch with details of their children's lives such as their likes and dislikes, accomplishments and developmental stages. 
Research has found considerable levels of distress amongst mothers in custody as a result of separation. As reported by Stanley and Byrne (2000), incarcerated mothers have reported feelings of anger, anxiety, sadness, depression, shame, guilt, decreased self-esteem and a sense of loss when separated from their children. Such anguish can not only affect the prisoner's mental health, but also their behaviour in custody.

\section{The Intergenerational Nature of Crime and Delinquency}

\section{Figure 1: The Contribution of Maternal Incarceration to the Intergenerational} Cycle of Crime

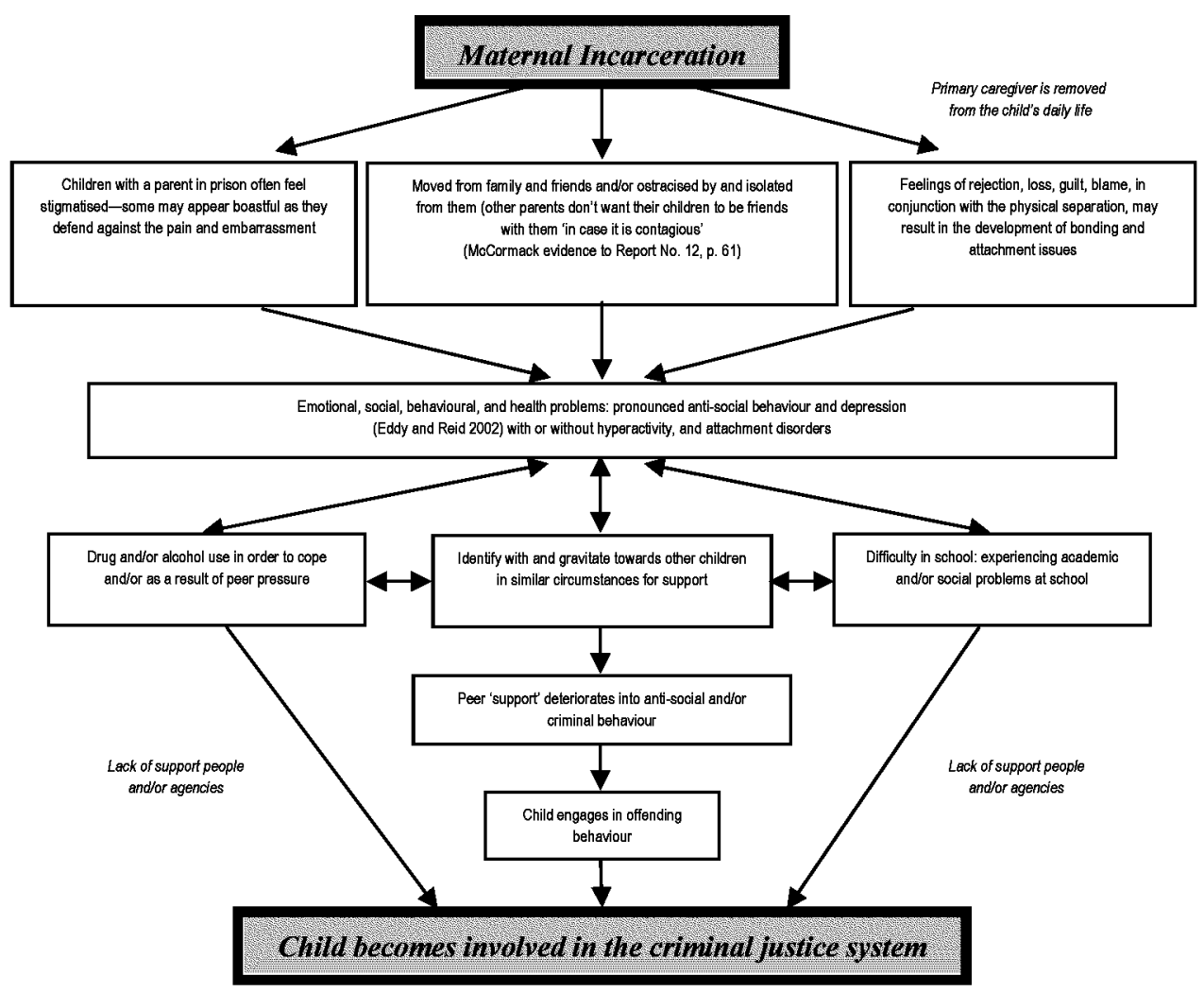

Inadequate parenting has long been reported to be a major precursor to a pathway of delinquency (Dowling and Gardner 2008), with early experiences of parenting likely to influence the societal choices made by a child or young adult and the likelihood of involvement in criminal behaviour (National Crime Prevention 1999). It has also been proposed that the mental, emotional, physical and financial hardship experienced by children of incarcerated parents may be a contributing factor to the intergenerational nature of crime and delinquency (Codd 2007). In fact, Woodward (2003: vii) argues that 
'imprisoning a parent increases the likelihood of their children becoming incarcerated by up to six times'. Whilst these contributing factors may overlap, this is not always the case.

Whilst the finite correlation between parent and child criminal activity is still debateable, the possibility of such a link is worth noting when designing intervention programs.

It is plausible that the promotion of healthy child-parent relationships, and responsive parenting, through the provision of a skills-based parenting program may contribute to the prevention of intergenerational incarceration. Based on available evidence, Figure 1 illustrates the potential impact of maternal incarceration on the perpetuation of the intergenerational cycle of crime with affected children.

\section{Parenting Programs for Prisoners}

Parenting programs within prisons are varied and widespread. Such programs aim to improve parenting skills and promote healthy child-parent relationships. They focus on parenting skills, relationship development and cohesion, child development, communication and self esteem (see for example, Luke 2002; Thompson and Harm 2000). Improvements in parent-child communication would be especially beneficial for families in which the child's behaviour, or the parent-child relationship, has been affected by parental incarceration, and where subsequent parenting skills will be required to manage difficulties experienced (Lange 1997).

Parenting programs may also ease re-entry of the prisoner into a parental role on release from custody (Hairston 1998). This may be of paramount importance to incarcerated mothers who are most likely to return to a primary caregiver role (Bruns 2006). As most mothers intend to reunite with their children upon release it has been suggested that strengthening and improving family interactions during incarceration should be a high priority (Young and Smith 2000). Maintaining family and community ties during and after incarceration, as promoted in parenting programs, may also decrease the possibility of recidivism (Hairston 1998). Along with substance abuse treatment, education, and job skills training, 'having a family to return to is one of the most important factors in an offender's successful re-entry into society' (Howard 2000:2). Studies have shown that prisoners who repair and maintain family relationships have reduced disciplinary problems in custody, improved mental health during their incarceration and on release, post-release success, and decreased recidivism (Fuller 1993 and Klein and Bahr 1996, cited in Stanley and Byrne 2000). Whilst reducing the negative effects of maternal incarceration on the child, such programs may result in a reduction in reoffending behaviour of the mothers, as well as the alleviation of the distress and anxiety associated with an enforced separation from their child.

Evaluations of parenting programs involving Australian prisoners are limited in number and tend towards methodological inconsistencies. Much of the existing research utilises non-standardised assessments, a lack of comparison groups, and an absence of follow-up or long-term assessments. There is some evidence to suggest that there are significant positive changes in prisoners in self-esteem, appropriate expectations of behaviour, corporal punishment, parent-child roles, and knowledge about child development (see LaRosa and Rank 2001; Showers 1993; Thompson and Harm 2000). As a result of these pro-social changes, Stanley and Byrne (2000:5) argue that such interventions 'might help these 
women, whilst imprisoned and upon release, to raise their children in more positive environments, reducing not only their own offending but the potential for their children in becoming the next generation of offenders'.

\section{The Mothering at a Distance (MAAD) Program}

In 2006, CSNSW in a collaborative initiative with Tresillian introduced the MAAD Program into the NSW correctional system. The MAAD Program consisted of four complementary programs:

1. An orientation program for the mothers on entry to the corrective services system.

2. A supported play program ('Stay and Play') for the children during prison visiting times.

3. A closed 10-session therapeutic mothers' group focusing on the development of parenting and maternal/child relationship skills.

4. An education and support program for corrective services staff to enable them to assume ongoing responsibility and facilitation of the Program enabling sustainability.

The principle objective of the MAAD Program was to develop strategies to enhance pro social parenting skills through increased maternal sensitivity and appropriate responsiveness to infant's signals or cues with the aim of guarding against the intergenerational cycle of crime.

An evaluation process was developed as an integral part of the Program's development and implementation. Quantitative and qualitative data were collected. Approval for this evaluation was provided by CSNSW and University of Technology, Sydney, Human Research and Ethics committees. The participants were provided with information prior to agreeing to participate in the evaluation and provided signed consent.

\section{Quantitative Research Method}

\section{(a) Descriptive Statistics}

The evaluation utilised descriptive statistics to present a profile of program participants, and to report on the number of women offenders commencing and completing the Program.

\section{(i) Demographic and Criminogenic Profile}

Descriptive statistics were used to present a profile of the demographic and criminogenic characteristics of all consenting participants of the Program. This profile includes the following factors:

- Demographic factors of participants: age, Aboriginal and Torres Strait Islander status, country of birth, language spoken at home, employment status, marital status, level of carer (primary/secondary/tertiary), number of dependents, number of pregnancies, number of children born, age left home, self-harm history, health issues, mental health issues, education attainment, and location of participant. 
- Demographic factors of participants' children: age, gender, birth order, single or multiple birth, identified health issues, identified behavioural issues, current medication(s), developmental delay, current carer, frequency of visits.

- Parenting characteristics of participants: parenting style and main parenting challenge(s) identified by the mothers.

- Criminogenic factors of participants: sentence length, court level, most serious offence, prior convictions, prior sentence type (imprisonment, periodic detention, community-based order), risk rating, security classification, and disciplinary charges/offences in custody.

\section{(ii) Trend (Output) Analysis}

The output analysis employed descriptive statistics to identify trends in the number of referrals and placement of participants to the MAAD Program. The analysis used flow data and included the number of participants in each program group over the duration of the evaluation period, as well as the attrition rate for each of these groups.

Analysis of the usage of the MAAD Program was conducted on data collected from all groups run from October 2006 until December 2008, and included the following factors:

- number referred to the Program

- self reported Aboriginal and Torres Strait Islander status of participants

- $\quad$ self-reported non-English speaking background (NESB) status of participants

- location where the Program is conducted

- Program participation

- attrition from the Program

- outcomes for participants of the Program (i.e. changes in parenting, maternal sensitivity, and communication with their children).

\section{Qualitative Research Method}

In addition to the collection of quantitative data, the evaluation included the use of qualitative research components to examine attitudinal and behavioural changes in participants' parenting, maternal sensitivity, and interactions with their children.

\section{(a) Appreciative Inquiry Approach}

Appreciative Inquiry is a common approach that identifies program strengths rather than weaknesses. As such, data collection and analysis focuses on the successful processes and outcomes, rather than problems and their causes. When used in program evaluation, Appreciative Inquiry involves 'collecting data about peak experiences of program participants and identifying factors that have contributed to the program's success' (Preskill and Catsambas 2006 cited in Hollero 2008:4).

In accordance with this method of inquiry, the evaluation included the administration of three narrative-based questionnaires designed to measure levels of trust and personal 
security that may lead to positive change in offender behaviour, and participants' understanding of issues affecting their child/ren's perception of trust and security.

\section{(i) The Participants' Pre- and Post-Program Interview Schedule}

The two interviews (pre- and post-Program) aimed to elicit indications of individual offenders' capacity for positive change in the following ways:

- positive language and narrative system change

- positive images of their future

- positive action in their relationships and appreciation of pro-social relations

- positive reinforcement and modelling uptake in a social learning environment

- increased motivation to decrease offending behaviour.

\section{(ii) The Participants' Evaluation Questionnaires}

A questionnaire was administered to participants at the completion of the group, and again eight weeks after the group, to evaluate the mothers' group and playgroup sessions. These questionnaires included questions on: overall satisfaction with mothers' group and playgroup sessions; participant's perceptions of their learning outcomes, and suggestions for improvements to the Program.

In relation to the follow-up questionnaire, only those participants who were still in custody, or had been released under the supervision of Community Offender Services at the time, were approached to respond. Due to the voluntary nature of the questionnaires, and the difficulty in obtaining responses from participants eight weeks after the Program's completion, the Research Advisory Group decided that three attempts would be made at follow-up before regarding the data as 'lost'.

\section{Program Outcomes}

\section{Level of Participation and Completion}

Between October 2006 and December 2008, the MAAD Program was conducted 16 times and was adapted for use for indigenous offenders when required. In total, 110 prisoners participated in the Program. This included 11 women who commenced the Program twice. Counting both instances for those who completed it twice, 68.2 per cent of participants (75) completed the Program.

The mean age of participants was 29 years, with age ranging from 19 to 45 years. The majority of the participants reported being the primary carer of at least one child, with three reporting being a secondary carer (i.e. grandmother, aunt, etc), and two reporting to be pregnant with their first child. In total, 119 children aged 0 to 5 years were reported by participants. In relation to care arrangements, whilst their mothers were in custody, the majority of these children ( 76.5 per cent) were living with relatives. A further 16 per cent were in care, while 5.9 per cent were living with their mother in custody. 


\section{Findings from Pre-Program Interviews}

Participants were interviewed prior to commencing the Program to gather information about their relationships with their children, their struggles with guilt and separation, and the parenting skills they wished to develop. They were interviewed again after completion of the Program to gauge their thoughts about, and experiences whilst on the Program.

When asked whether they ever feel a sense of guilt over their level of parent skills, the majority of women reported that they did, with a number stating that they 'always feel guilty'. While some of the mothers reported feeling guilty for punishing their children's behaviour and sending them to their room, the majority of participants reported feeling this way as a direct result of being in custody, for example 'not being with him when he needs me', 'not watching him grow up' or 'letting them down'. Some similar comments included:

- 'I feel guilty that I'm not there to protect her, to look after her and love her, to be the mother ... I'm not the one there to put her to bed, I'm not the one that's getting up at night making her bed, I'm not the one to take her to the doctors if she's sick, I'm not there to nurture her, I'm not there to do nothing and that hurts me the most'.

- 'I feel guilty that I'm not there for him and if I didn't do what I did I would be out there with him'.

When asked how they handled feelings of guilt, some of the respondents admitted to 'lock(ing) them in', while others reported talking to counsellors, correctional staff, family, or other prisoners. Some of the women stated that they keep in close contact with their children 'by phone, by mail, I always make her things and send them to her, I always write her letters'.

Many of the women acknowledged that, while the children are happy to see them, they are 'heartbroken', 'sad', 'empty', and 'confused' when they have to leave a visit in the prison. When asked about this experience, one mother stated 'they don't want to go and they cry and scream out and things and I don't like it and I don't think its [sic] fair on them ... (they feel) angry, confused, upset ... they tell me they don't understand why mummy can't come home'.

When asked to describe what happens when their child has to leave after prison visiting time, the majority of the women reported crying and misbehaviour by their children. Some such comments included:

- 'sometimes she gives me dirty looks or frowns at me when she's leaving, like puzzled, like 'why am I going?'. It makes me upset too'

- 'my sister would bring him down to see me and she said he played up terribly when he left and I think that was really hard for my sister, or for both of them'.

The main parenting skills that the prisoners identified as most eager to develop included discipline strategies and reconnecting with their children post release. Discipline strategies, or 'ways of dealing with children's behaviours, challenging behaviours ... tantrums', was identified by a number of women, with one woman stating ' $I$ think I'll have problems when I get home ... how to say no, I don't want to feel bad for saying no', while another stated that she needed to learn 'patience, and how to deal with situations without getting angry'. Prisoners also requested skill development in re-establish relationships with their children when they are released from custody, with one woman stating that she would like to learn 'how to connect with her again when I get out and see her ... how to rebuild that trust'. 


\section{Attitudinal Changes in Approach to Parenting}

Overall satisfaction with the Program was high, with the majority of respondents to the survey stating that they were 'extremely' or 'mostly' satisfied. One respondent stated: 'it gave me inspiration to not give up. I thought it was great', and another stated: 'it was the best group I'd done'.

Participants were asked to identify some of the best things about the Program. Responses included learning about child development, 'learning to see the world through toddlers' eyes', 'learning new ways on how to cope with tantrums', and 'learning techniques to help discipline children'. In addition, a number of respondents identified learning to understand their child's behaviour and why they do the things they do, and learning to communicate and interact with their child as the best things about the Program.

When asked whether they felt more confident about looking after their child since completing the Program, the majority of participants stated that they did. When asked about the ways they feel more confident, respondents provided the following comments: 'I am more confident that I can provide for their needs better and live up to their expectations of me' and 'I feel more confident because I know how to tackle situations'.

Participants were asked whether they had changed how they react when their child is upset or demanding. In response, 69.4 per cent of the respondents stated that they had changed, providing the following examples: 'I get down to his level and talk face to face and I find it works a lot' and 'using positive reinforcement ... I learnt to ignore negative behaviour and praise good'.

Similar numbers of respondents stated that they would 'strongly agree' or 'agree' with the comments 'the group has helped me feel closer to my child' (82 per cent immediately and 83 per cent at follow-up) and "the group has helped me feel better about caring for my child' ( 89 per cent both immediately and at follow-up).

Due to the emotional nature of the Program, one participant also identified the difficulty she experienced in 'talking in front of the other girls' stating that she 'found [her] self holding back on what [she] said'.

\section{Findings from Post-Program Interviews}

Upon completion of the Program, a high number of prisoners reported that they believed that the whole program would be helpful to them on release from prison. More specifically, the majority reported that learning different ways of communicating and interacting with their children would be of great benefit to them on release, in particular, learning 'how to come down to their level and active listening'.

Other beneficial skills identified included learning 'how to discipline', 'limit setting', and 'how to talk to them when they have a tantrum'. In addition, one prisoner acknowledged that she needed to change her own behaviours in order to be a good role-model for her children. She stated, 'you know how they're parrots...I swear a lot and I see my daughters acting the way I do even though I haven't been around all their lives. My daughter's even starting to dress like me ... a 6 year old wanting to wear little skirts and stuff is just ... just changing my behaviour and trying to be a good role-model'. 
It is interesting to note that when asked about what made them feel safe, the majority of prisoners stated that having a stable home, being with their children, or knowing their children are happy and safe, made them feel safe. Similarly, when asked what makes their children feel safe, the majority of prisoners believed that their physical presence was paramount to their child's care. Some such comments included:

- 'knowing that I'm home, knowing that I'm there for them and that they can turn to me whenever they need me'

- 'I think he feels safe when I'm there with him and he doesn't have the fear of me going away'

A number of the women acknowledged putting their children first, when asked about the changes that should take place to improve the quality of your life with their children on their release from prison. In conjunction with eliminating the negative lifestyle choices that are likely to return the women to prison (i.e. drug use, 'house hopping', and associating with 'the wrong people'), participants recognised the need to 'spend more time building the bond back', 'focus more on myself so I've got a safe atmosphere for her', and 'concentrate on my children's needs'.

Similarly, when asked what their one wish for their relationship with their child on the outside would be, many of the participants identified the wish 'to all be together' as 'a happy family' and 'to have the security that I'd never leave them again'.

As a result of completing the Program, prisoners appeared to recognise that their children are individuals with their own thoughts and feelings. For example, some of the things participants reported learning about their children during this Program included:

- ' 'how much they miss me and how much they really do need me'

- 'that she's at an age where I feel its [sic] so important for me to be there, turning into a young woman, and I actually feel very confident at being able to do that with her'

When asked what they had learnt about themselves during this Program, many of the participants reported increases in confidence, stating that they learnt that they are 'not such a bad mum', were 'doing an ok job and now I can do a better job', or 'that it can be done' and they have 'got the potential to be a good mum'. Others reported learning the following:

- 'I've learnt not to discipline my kids like I used to. I've learnt to be a better mum and to be a better person. I've recognised that when my kids are naughty I shouldn't smack them. I should just sit down and talk to them'

- 'how selfish I'd been to get locked up'

- 'how much I've got to change my behaviour - I don't want my kids growing up and running a muck like I have'

Although there was some evidence that prisoners who participated in the Program gained insight into their parenting behaviour and habits, there is no evidence to suggest that participation in this Program impacted on attitudinal change towards criminal behaviour. The prisoners did not demonstrate that they gained insight into connections between lifestyle choices i.e. criminal behaviour, drug use etc and improving the quality of life and well-being of their child. This is an important 'gap' in the perceptions of the importance of connections and understanding of pro-social lifestyles that would benefit from further exploration. 


\section{Challenges in Program Facilitation and Program Sustainability}

Despite evidence of positive outcomes, the introduction of parental education within the correctional system is a complex endeavour. Complexities include: constraints relating to access, security, availability of resources, and the differing needs and experiences of incarcerated parents. Several issues regarding the facilitation of such programs will require resolution if the MAAD Program is to maintain its current momentum.

The majority of facilitation issues were systemic in nature, that is, not with the Program itself, but rather with the custodial context in which it was conducted. Most commonly cited were delays, resulting from correctional centre security regimes, and interruptions caused by the distraction of continuous intercom communications, prisoner transfers, limited, or interrupted, access to participants due to competing program priorities and competition for program venue space.

Specific issues were also raised in relation to parent-child/ren contact levels. One of the greatest disappointments cited by prisoners was that of not being able to get certain program components operating. While the prisoners who had their children living with them in custody, and those with regular visits, could readily practise their parenting skills during the supported play group work, those with little or no contact with their children were unable to do so. This problem resulted in an increase in prisoners reporting feelings of guilt and jealousy, which impacted on the program outcomes. In order to reduce the possibility of such potential negative effects, it may be beneficial to conduct more targeted groups where there are no substantial differences in levels of parental contact.

Issues of program sustainability are inextricably linked with program facilitation. Sustainability of programs requires a number of key elements including: local concerns, an iterative process, an investment in capacity, leadership, cooperation, linkages to other programs, tangible outcomes, and adequate resources (Caputo, Kelly and Jamieson 2004). Evidence was gathered on whether the programs demonstrated an adherence to the general principles of sustainability. There is some strong evidence that aspects of sustainability of the MAAD Program were established such as adequate funding, iterative process and realised outcomes. However, there is also some evidence to suggest that elements, such as the development of program linkages and stronger leadership, would benefit the Program.

\section{Conclusion}

The evaluation of the MAAD Program documented the development and delivery of the Program between October 2006 and December 2008, as well as the program outputs and self-reported effects on parenting attitudes and behaviours.

Many of the comments made by participants suggested that the Program was successful in meeting its primary objectives of enabling the women prisoners to develop appropriate parenting strategies and skills. In particular, a high proportion of prisoners reported that the Program assisted them to feel more confident about looking after their child; more able to understand their child; closer to their child; and better about caring for their child. In addition, they reported that they 'listen more to what [their] child is telling [them]' and that they 'don't get as angry with [their] child' as a result of their participation in the Program. 
While the majority of responding program facilitators reported that they thought the prisoners were more confident in their ability to care for their child/ren, few staff were able to confirm whether "the program has helped the women to act in a more sensitive and responsive way when interacting with their children', or 'the children's behaviour has improved during visiting time' due to the lack of exposure to interactions between participants and their children. As a result, there is little evidence as to whether the Program has met its objectives of reducing the distress caused by separation due to incarceration for female prisoners and their young children, and reducing the trauma for young children caused by separation and visiting their mother within a prison setting.

While it can be argued that the changes in parenting attitudes and increases in self-esteem described in the evaluation may result in positive changes in criminogenic attitudes and behaviours, and a decrease likelihood of intergenerational crime, this is a preliminary finding only and the results cannot be regarded as conclusive. In particular, as effectiveness was primarily measured through feedback provided by prisoners themselves, rather than through the objective observation of mother-child interactions, caution is needed in interpreting the results. For example, it cannot be known whether the results reflect actual changes in the parenting attitudes and behaviours of participants, or merely the reporting of socially desirable responses.

The positive responses provided through participants' follow-up evaluations should also be interpreted with caution as those who responded may not be representative of all MAAD Program participants. While all contactable participants of the Program were given the opportunity to complete a follow-up evaluation, 48 per cent chose to respond. It is possible that those who were less positive about the Program chose not to respond or some participants may have chosen to put the experience of incarceration behind them.

To more conclusively determine the effectiveness of the MAAD Program, further evaluation is required, preferably using a quasi-experimental design. Participants will need to be compared on post-Program parenting skills, attitudes, and reoffending, with a suitable comparison group of prisoners who did not participate in the Program. Future research on the effects of the Program could also involve a longitudinal study of the children involved in order to evaluate the effects on the intergenerational cycle of crime.

Finally, although there was some evidence that prisoners who participated in the Program gained insight into their parenting behaviour and habits, there is no evidence to suggest that participation in this Program impacted on attitudinal change towards criminal behaviour. The seeming disconnect between criminal behaviour, improved parenting skills and the well-being of one's child would benefit from further exploration.

\section{References}

Anti-Discrimination Commission Queensland (2006) Women in Prison: A Report by the Anti-Discrimination Commission, Queensland

Australian Bureau of Statistics (2008) Prisoners in Australia, accessed online at $<$ http://www.abs.gov.au>

Bruns DA (2006) 'Promoting Mother-Child Relationships for Incarcerated Women and Their Children', Infants and Young Children, vol 19 no 4, 308-22 
Bushfield S (2004) 'Fathers in Prison: Impact of Parenting Education', The Journal of Correctional Education, vol 55 no 2, 104-16

Butler T and Milner L (2003) The 2001 New South Wales Inmate Health Survey, NSW Corrections Health Service, Sydney

Caputo T, Kelly K and Jamieson W (2004) A Portrait of Sustainable Crime Prevention Selected Canadian Communities, Carleton University

Codd H (2007) 'Prisoners' Families and Resettlement: A Critical Analysis', The Howard Journal, vol 46 no $3,255-63$

Corben S (2008) NSW Inmate Census 2007: Summary of Characteristics, Statistical Publication No 31, NSW Department of Corrective Services

Cunningham A (2001) 'Forgotten Families - The Impacts of Imprisonment', Australian Institute of Family Studies, no 59, Winter, 35-8

Dawe S, Frye S, Best D, Moss D, Atkinson J, Evans C, Lynch M and Harnett P (2007) Drug Use in the Family: Impacts and Implications for Children, Australian National Council on Drugs, Canberra

Dowling S and Gardner F (2008) Parenting Programmes for Improving the Parenting Skills and Outcomes for Incarcerated Parents and their Children (Protocol), The Cochrane Collaboration, John Wiley and Sons Ltd

Eddy JM and Reid JB (2002) 'The Anti-social Behaviour of Adolescent Children of Incarcerated Parents: A Developmental Perspective', Paper presented at 'From Prison to Home: The Effect of Incarceration and Reentry on Children, Families, and Communities', 30-31 January 2002

Hairston CF (1998). 'The Forgotten Parent: Understanding the Forces that Influence Incarcerated Fathers' Relationships with their Children', Child Welfare, vol 77 no 5, 617-37

Healy K, Foley D and Walsh K (2000) Parents in Prison and their Families: Everyone's Business and No-One's Concern, Catholic Prisons Ministry, Brisbane

Healy K, Foley D and Walsh K (2001) 'Families Affected by the Imprisonment of a Parent: Towards Restorative Practices', Children Australia, vol 26 no 1, 12-19

Hollero M (2008) Using Appreciative Inquiry in Correctional Settings: A Literature Review, NSW Department of Corrective Services (unpublished)

Howard S (2000) 'Fathering behind Bars', Paper presented at the Focus on Fathering Symposium, $7^{\text {th }}$ Australian Institute of Family Studies Conference, 24-26 July 2000, Sydney, Australia, accessed online at $<\mathrm{http}: /$ www.aifs.gov.au/institute/afrc7/howard.html $>$

Lange SM (1997) Parent Training in Corrections: Mission, Methods, Materials and Best Practices, Mountainview Youth Correctional Facility and Fordham University Graduate School of Education

LaRosa JJ and Rank MG (2001) 'Parenting Education and Incarcerated Fathers', Journal of Family Social Work, vol 6 no 3, 15-33

Loy M (2000) 'A Study of the Mothers and Children's Program in the NSW Department of Corrective Services', Paper presented at the Women in Corrections: Staff and Clients Conference convened by the Australian Institute of Criminology in conjunction with the 
Department of Correctional Services South Australia, 31 October-1 November 2000, Adelaide, Australia

Luke KP (2002) 'Mitigating the Ill Effects of Maternal Incarceration on Women in Prison and their Children', Child Welfare, vol 81 no 6, 929-48

Miller K (2006) 'The Impact of Parental Incarceration on Children: An Emerging Need for Effective Interventions', Child and Adolescent Social Work Journal, vol 23 no 4, 472-86

National Crime Prevention (1999) Pathways to Prevention: Developmental and Early Approaches to Crime in Australia, National Crime Prevention, Attorney-General's Department, Canberra

National Scientific Council on the Developing Child (2004a) Young Children Develop in an Environment of Relationships, Working Paper No. 1, accessed online at $<\mathrm{http}: / /$ www.developingchild.harvard.edu $>$

National Scientific Council on the Developing Child (2004b) Children's Emotional Development is Built into the Architecture of their Brains, Working Paper No. 2, accessed online at $\langle\mathrm{http}: / / \mathrm{www}$.developingchild.harvard.edu $>$

Quilty S, Levy MH, Howard K, Barratt A and Butler T (2004) 'Children of Prisoners: A Growing Public Health Problem', Australian and New Zealand Journal of Public Health, vol 28 no 4, 339-43

Showers J (1993) 'Assessing and Remedying Parenting Knowledge among Women Inmates', Journal of Offender Rehabilitation, vol 20 no 1/2, 35-46

Standing Committee on Social Issues (1997) A Report into Children of Imprisoned Parents, Report No 12, Legislative Council, Parliament of New South Wales, July 1997

Stanley E and Byrne S (2000) 'Mothers in Prison: Coping with Separation from Children', Paper presented to the Women in Corrections Conference, October/November 2000, Adelaide, Australia

Thompson P and Harm N (2000) 'Parenting from Prison: Helping Children and Mothers', Issues in Comprehensive Pediatric Nursing, vol 23 no 2, 61-81

Travis J (2005) 'Families and Children', Federal Probation, vol 69 no 1, 31-42

Tudball N (2000) Doing It Hard: A Study of the Needs of Children and Families of Prisoners in Victoria, The Victorian Association for the Care and Resettlement of Offenders (VACRO)

Victorian Health Promotion Foundation (2004) The Health Costs of Violence: Measuring the Burden of Disease Caused by Intimate Partner Violence - A Summary of Findings, Victorian Department of Human Services and VicHealth, accessed online at $<$ http://www.vichealth.vic.gov.au/ /media/ProgramsandProjects/MentalHealthandWellBein $\mathrm{g} /$ DiscriminationandViolence/IntimatePartnerViolence/ipv.ashx $>$

Western Australia (WA) Department of Corrective Services (2009) Profile of Women in Prison 2008: Final Report, Government of Western Australia

Woodward R (2003) Families of Prisoners: Literature Review on Issues and Difficulties, Occasional Paper No 10, accessed online at <http://www.facsia.gov.au/research/ op10/OP_No_10.pdf> 
Young DS and Smith CJ (2000) 'When Moms are Incarcerated: The Needs of Children, Mothers and Caregivers', Families in Society, vol 81 no 2, 130-41 